\title{
Correlation between Inflammation and Fibrinolysis Impairment on Central Obesity: A Study for hsCRP, PAI-1, PAP and TAFI
}

\author{
Winni Agustiani ${ }^{1,2 *}$, Mansyur Arief ${ }^{2}$, and Ilhamjaya Patellongi ${ }^{2}$ \\ ${ }^{1}$ Prodia Clinical Laboratory, JI. Wastukencana no.38, Bandung, Indonesia \\ ${ }^{2}$ Faculty of Medicine, Hasanuddin University, Jl. Perintis Kemerdekaan Km.10, Makassar, Indonesia \\ *Correspondence: winni.agustiani@prodia.co.id, winni_agustiani@yahoo.com
}

\section{Abstract}

ACKGROUND: Inflammation in the vascular wall plays an important role in the pathogenesis of atherosclerosis. Current studies have shown that increase of systemic inflammatory marker like the acute phase component $\mathrm{C}$-reactive protein (CRP) are associated with an unfavorable progression of disease and an increased risk for acute cardiovascular events. Recently, a close association of Metabolic Syndrome (MetS) with hemostatic abnormalities has been reported. Among hemostatic abnormalities, an increase in plasminogen activator inhibitor (PAI)-1, a strong inhibitor of fibrinolysis, is considered a core feature of MetS. High PAI-1 concentrations may be associated with thrombus formation, also causing cardiovascular events. Therefore, we investigated the association between markers for chronic inflammation (CRP) and the markers of fibrinolytic impairment (PAI-1, PAP, TAFI) in subjects with central obesity.

METHODS: This was a cross-sectional study in 80 male Indonesian subjects, aged 30-60 years old with central obesity, conducted from January to March 2008 in Bandung.

RESULTS: The study results showed that there was a difference of PAI-1 levels between MetS and Non-MetS group. There were significant correlations between hsCRP and PAI-1 $(r=0.252, p=0.024)$, hsCRP and PAP $(r=$
$0.253, \mathrm{p}=0.024)$, and also between PAI-1 and PAP ( $\mathrm{r}=$ $-0.239, p=0.033$ ) respectively. But, no correlation found between hsCRP and TAFI.

CONCLUSIONS: There was correlation between inflammation and fibrinolysis impairment on central obesity. Concentrations oh hsCRP, PAI-1 and TAFI were significantly higher in MetS.

KEYWORDS: Inflammation, Fibrinolysis Impairment, hsCRP, PAI-1, PAP, TAFI.

Indones Biomed J 2011 ; 3 (2) : 127-132

\section{Introduction}

Low-grade systemic inflammation can interfere with insulin action. It seems to play a role in pathobiology of various components of MetS such as obesity, hypertension and insulin resistance (1). In addition, inflammation has a pivotal role in the initiation or progression of atherosclerosis.Plasma level of high-sensitivity C-reactive protein (hsCRP), a marker of inflammation, has been reported as a simple predictor of future cardiovascular (CVD) events (2), especially in the setting of MetS.

Since its recognition during the 1980 s, the main pathomechanism of MetS has been considered as hyperinsulinemia, impaired glucose homeostasis, dyslipidemia, and hypertension. Subsequently, it expands to include hyperuricemia, impaired postprandial triglyceride 
metabolism, microalbuminuria, endothelial dysfunction, subclinical inflammation, and adverse changes of fibrinolytic and thrombotic factors (3).

Obviously, MetS is associated with abnormal fibrinolytic and atherosclerosis. Moreover, high plasma concentrations of PAI-1 and decrease tPA activity would reflect a state of fibrinolytic dysfunction. Fibrinolytic dysfunction increases the propensity to develop arterial thrombosis, which in turn may increase CVD in people with MetS (4).

In addition, hyperglycemia selectively stimulates coagulation irrespective of insulin levels. Likewise, hyperinsulinemia inhibits fibrinolysis (primarily by enhancing PAI-1 secretion) irrespective of glucose concentrations. Hence, the presence of both hyperglycemia and hyperinsulinemia (such as in type 2 diabetic patients) has a strong procoagulant effect by increasing coagulation and inhibiting fibrinolysis (5).

Plasmin is the enzyme responsible for fibrinolysis. Its production is accelerated by the presence of fibrin and inhibited by PAI- 1 . Free plasmin is rapidly inhibited by $\alpha 2$-antiplasmin, and the resulting plasmin $\alpha 2$ antiplasmin complex (PAP) indicates plasmin generation and fibrinolysis. There upon, elevated levels of PAP are associated with the incidence of acute MI in the elderly (6).

A new inhibitor of fibrinolysis has been recently identified in plasma. As this protein is activated by thrombin and then downregulates fibrinolysis, it has been named thrombin-activatable fibrinolysis inhibitor (TAFI) (7). And TAFI is a recently discovered glycoprotein combining coagulation and fibrinolysis. Hence, suppresion of the fibrinolytic system is associated with increased CVD morbidity and mortality(8).

Until recently, there has been no clinical evidence as yet that shows the correlation between inflammatory markers and fibrinolysis impairment, as represented by PAI-1, PAP and TAFI in MetS.

\section{Methods}

\section{Study Design and Subjects}

This was a cross-sectional study that recruited 80 Indonesian men, aged between 30-60 years old. Subjects with symptoms of infection(s), abnormal liver function test, consuming either anticoagulant or antiplatelet drugs or suffering any underlying acute condition as assessed by a medical interview were excluded. Written informed consent was obtained from all subjects. This study was approved by the Ethics Committee of the Faculty of Medicine, Padjadjaran University - Bandung (No.: 26/ FKUP-RSHS/KEPK/Kep./EC/2008). The period for recruitment of the study subjects lasted from January until March 2008 in Bandung, West Java.

\section{Clinical Measurements}

Heights, body weights and waist circumferences were measured by the standard methods and the Body Mass Index (BMI) was calculated according to the standard formula. Venous blood sample were collected in the morning after 12-hour overnight fasting. The samples were examined in Prodia Clinical Laboratory.

\section{Laboratory Analysis}

Measurements of Creatinine and SGPT (U/L) were carried out by IFCC method without pyridoxal phospate activation. Fasting plasma glucose $(\mathrm{mg} / \mathrm{dL})$ was measured using heksokinase method. Then, HDL-cholesterol (mg/ $\mathrm{dL})$ and triglyceride $(\mathrm{mg} / \mathrm{dL})$ were respectively determined using homogenous method and GTO-PAP method. All of this serum concentration were measured in Modular (Roche Diagnostics).

Serum concentration of $\mathrm{hsCRP}(\mathrm{mg} / \mathrm{L})$ was measured by immunochemiluminescent assay of Immulite 2000 (Diagnostic Products Corporation). Concentration of PAI-1 (ng/dL) measured by Enzyme Linked Immunoassay /ELISA (Technoclone) while concentration of PAP (ng/dL) was determined by Enzyme Linked Immunoassay/ELISA (Technoclone). TAFI concentration $(\mu \mathrm{g} / \mathrm{dL})$ was assayed by Enzyme Linked Immunoassay/ELISA (Cedarlane).

\section{Statistical Analysis}

Statistical analysis were conducted using the SPSS for Windows version 11.5 software (SPSS Inc. Chicago, IL. USA). Distribution of continuous variables were assessed for normality using Kolmogorov-Smirnov and for variance homogeneity using Leven's test. Independent t-test was used to confirm the diference between variables in MetS group and that without MetS. Linear regression analysis was used to prove the correlation between variables. The results were presented in narration and in tables and graphs. P-values lower than 0.05 were considered as statistically significant. 


\section{Results}

There was difference (using Independent Sample t-Test) in hsCRP and PAI-1, PAP and TAFI concentration between MetS and Non MetS group. A significant increase $(\mathrm{p}=$ 0.033 ) of hsCRP, PAI-1, PAP and TAFI concentration was found in MetS group.
Significant linear correlations between hsCRP and PAI-1 $(r=0.252 ; p=0.024)$ and between hsCRP and PAP $(r=0.253 ; p=0.024)$ were found as shown in the following graphs or figures:

Table 1. Clinical Characteristics

\begin{tabular}{lcccc}
\hline & Mean $( \pm \mathrm{SD})$ & Median & Min - Max & p \\
\hline Age & $44.19( \pm 8.25)$ & 44.00 & $31-60$ & 0.172 \\
Heights $(\mathrm{cm})$ & $168.04( \pm 6.73)$ & 168.25 & $150-182$ & 0.866 \\
Weights $(\mathrm{cm})$ & $78.67( \pm 9.18)$ & 77.25 & $59-107$ & 0.133 \\
Waist Circumference $(\mathrm{cm})$ & $98.77( \pm 6.18)$ & 97.50 & $90-117$ & 0.061 \\
BMl $\left(\mathrm{kg} / \mathrm{m}^{2}\right)$ & $27.81( \pm 3.09)$ & 27.30 & $21.7-37.5$ & 0.915 \\
Diastole $(\mathrm{mmHg})$ & $123.44( \pm 16.12)$ & 120.00 & $90-190$ & 3.618 \\
Systole $(\mathrm{mmHg})$ & $85.94( \pm 13.17)$ & 80.00 & $70-140$ & 1.720 \\
\hline
\end{tabular}

Table 2. Laboratory Characteristics

\begin{tabular}{lcccc} 
& Mean $( \pm \mathrm{SD})$ & Median & Min - Max & p \\
\hline Creatinin $(\mathrm{mg} / \mathrm{dL})$ & $0.89( \pm 0.14)$ & 0.88 & $0.62-1.39$ & 0.355 \\
GFR $(\mathrm{mL} / \mathrm{min})$ & $120.93( \pm 26.81)$ & 118.19 & $60.70-212.40$ & 0.914 \\
SGPT $(\mathrm{U} / \mathrm{L})$ & $36.06( \pm 20.01)$ & 29.00 & $10-103$ & 0.956 \\
Fasting Glucose $(\mathrm{mg} / \mathrm{dL})$ & $101.60( \pm 51.03)$ & 87.50 & $69-395$ & 2.701 \\
HDL $(\mathrm{mg} / \mathrm{dL})$ & $41.15( \pm 8.20)$ & 40.00 & $26-62$ & 0.332 \\
Triglyceride $(\mathrm{mg} / \mathrm{dL})$ & $192.65( \pm 124.49)$ & 163.50 & $45-907$ & 0.979 \\
hsCRP $(\mathrm{mg} / \mathrm{L})$ & $2.36( \pm 2.06)$ & 1.54 & $0.20-9.51$ & 0.919 \\
PAP $(\mathrm{ng} / \mathrm{dL})$ & $73.41( \pm 23.89)$ & 72.22 & $21.75-124.30$ & 0.838 \\
PAl-1 $(\mathrm{ng} / \mathrm{dL})$ & $39.10( \pm 20.73)$ & 36.05 & $6.87-103.90$ & 0.253 \\
TAFI $(\mu \mathrm{g} / \mathrm{dL})$ & $8.09( \pm 1.52)$ & 7.88 & $4.93-12.41$ & 0.503 \\
\end{tabular}




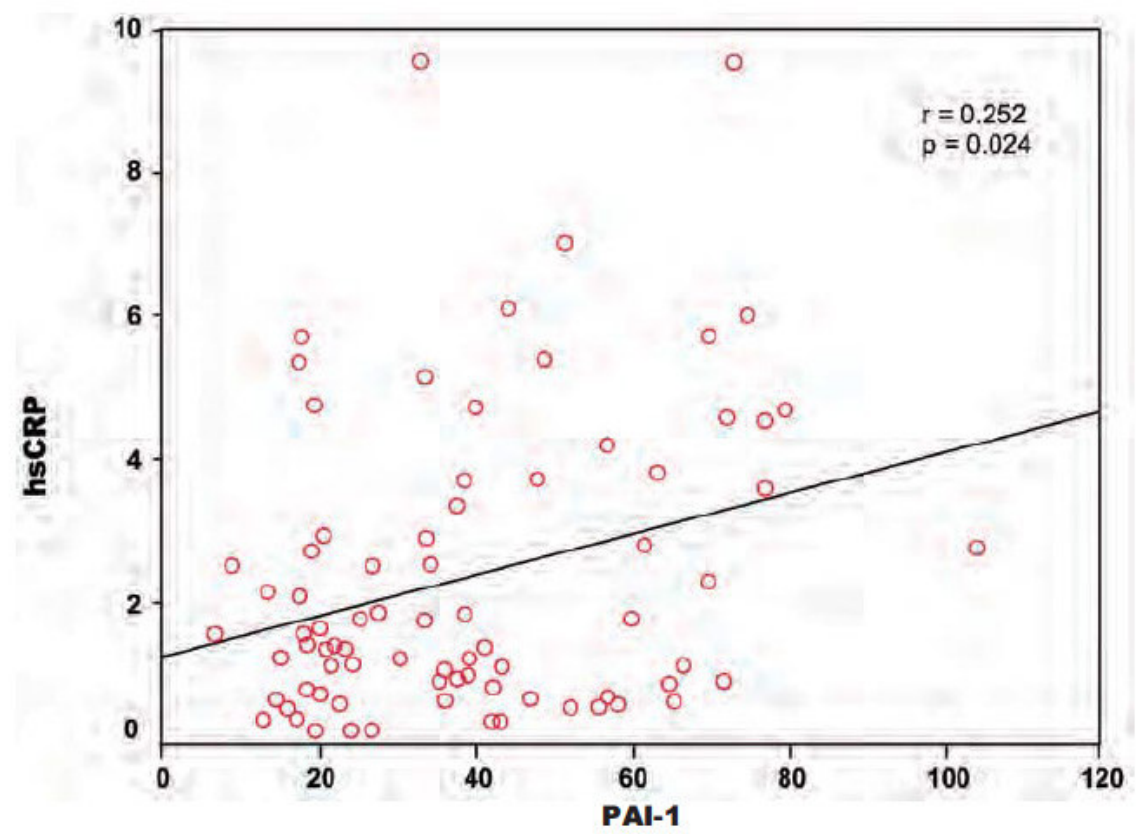

Figure 1. Significant Linear Correlation between hsCRP (mg/L) and PAl-1 (ng/dL).

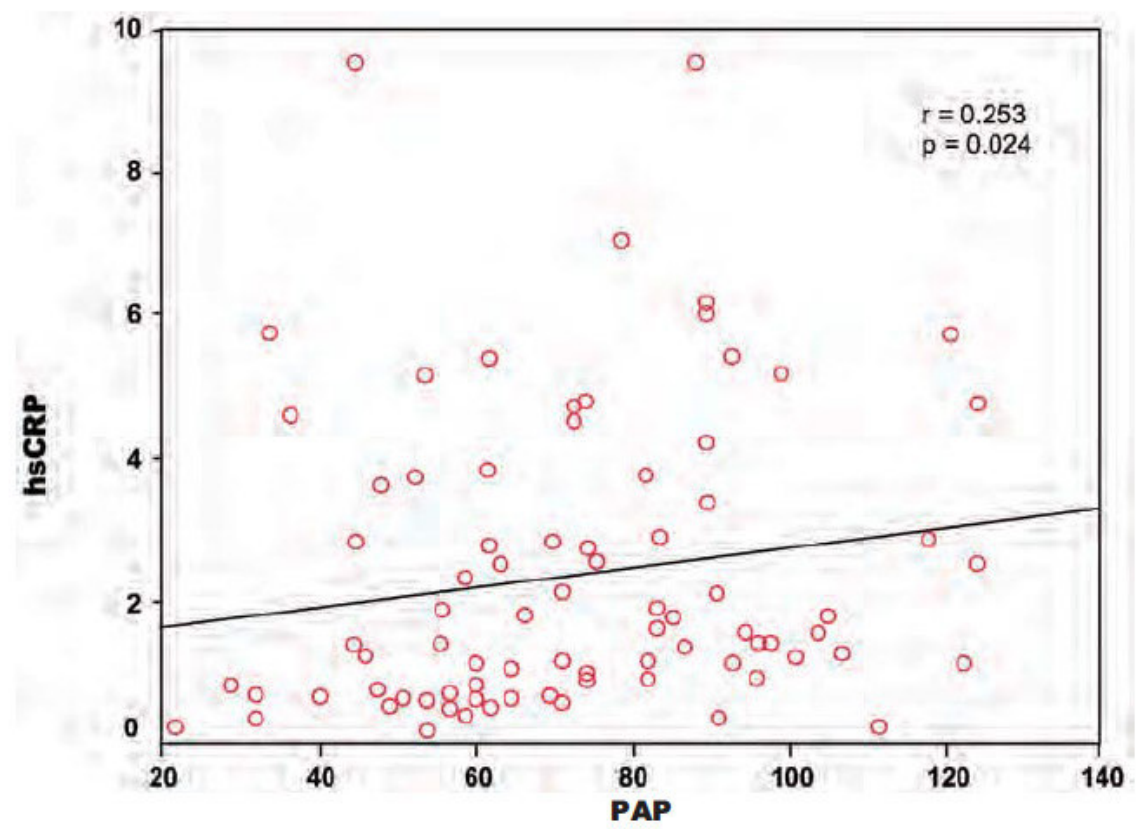

Figure 2. Significant Linear Correlation between hsCRP (mg/L) and PAP (ng/dL). 
In order to confirm pure (partial) correlations between hsCRP, PAI-1, PAP and TAFI, the partial correlation test was conducted, the results of which are as follows (table 3 ). Result of the partial correlation test showed that correlation values between hsCRP - PAI-1 and hsCRP - PAP became stronger, otherwise correlation between PAI-1 - PAP became weak.

\section{Table 3. Results of Partial Correlation Test}

\begin{tabular}{lllllllll} 
& \multicolumn{3}{c}{ Bivariat Correlation Test } & \multicolumn{3}{c}{ Partial Correlation Test } \\
& hsCRP & PAl-1 & PAP & TAFI & hsCRP & PAl-1 & PAP & TAFI \\
\hline hsCRP & 1 & $0.252^{*}$ & $0.253^{*}$ & 0.044 & 1 & $0.333^{*}$ & $0.326^{*}$ & 0.018 \\
PAl-1 & $0.252^{*}$ & 1 & $-0.239^{*}$ & -0.114 & $0.333^{*}$ & 1 & $-0.222^{*}$ & -0.070 \\
PAP & $0.253^{*}$ & $-0.239^{*}$ & 1 & 0.196 & $0.326^{*}$ & $-0.222^{*}$ & 1 & 0.175 \\
TAFI & 0.044 & 0.196 & -0.114 & 1 & 0.019 & -0.070 & 0.175 & 1 \\
\hline
\end{tabular}

\section{Discussion}

Significant difference in PAI-1 level between 2 groups (MetS and Non MetS) confirmed that it was closedly associated with components of MetS and showed a clear relationship between PAI-1 and BMI. This suggests that obesity is associated with PAI-1 concentration. This protein is synthesized in many tissues, likewise the main production site of this is in the adipose tissue (7).

PAI-1 increases in obesity and in subjects with insulin resistance and is also related with another cardiovascular risk representing impaired coagulation and fibrinolysis. Those abnormalities induced initiation and progression of atherosclerosis, as shown by increased inflammation and endothelial dysfunction $(9,10)$.

Recently, many studies have indicated that patients with medium or high CRP plasma levels are associated with higher levels of PAI-1 antigen at baseline compared with those with low hsCRP levels. This inflammatory marker may reflect the presence and severity of atherosclerosis and coronary plaque. It has been shown that inflammatory cytokines are able to induce procoagulant and antifibrinolytic activities in vascular cells. It induces the production of PAI-1 in endothelial cells and might also promote atherotrombosis. It increases IL- $1 \beta$ and TNF- $\alpha$ concentration, and later the increasing IL- $1 \beta$ and TNF- $\alpha$ will promote inhibition of tPA activity. Further, hsCRP also increase IL-8 concentration through NF- $\kappa B$. This mechanism will increase IL-1 and TNF- $\alpha$ (11).
This study showed that there was a significant correlation between hsCRP-PAI-1 and hsCRP-PAP. However, if the subjects are assessed between the two groups (MetS vs Non MetS group), significant correlation only occured between hsCRP and PAI-1 in MetS.

This study confirmed that there was no correlation between hsCRP and TAFI concentration. While in another study (7) proved otherwise. This might be possible because the subjects of the other study (7) were T2DM patients in whom greater risk existed than in those in our study. Another study (12) showed that coefficient corelation of PAI-1 and insulin resistance was greater than TAFI and insulin resistance. This confirmed that increasing TAFI concentration was not related to metabolic marker in MetS. Furthermore, there was no correlation between TAFI and CRP in obese subject (13).

In terms of fibrinolysis impairment, this study confirmed a correlation between PAI-1 and PAP, whilst no correlation was found with TAFI. This correlation is similar with that in the previous study done on T2DM patients (7). PAP was found in low concentration in T2DM patients, and it was negatively correlated with PAI-1 concentration and not correlated with TAFI. This might be due to differences in regulation and circulation. TAFI is more regulated in genetic basis that metabolic one as compared with PAP and PAI-1.

The partial correlation test showed that pure correlation value between hsCRP-PAI-1 and hsCRP-PAP became stronger, while correlation between PAI-1-PAP confirmed otherwise. This indicated that PAI-1 and PAP interfered each other in particular in the context of inflammation, as shown in T2DM $(6,7)$. 


\section{Conclusion}

Tthere was a linear correlation between inflammation and fibrinolytic impairment in subjects with central obesity. Concentrations of hsCRP, PAI-1 and TAFI were significantly elevated in MetS.

\section{Acknowledgement:}

The authors thank the Prodia Education and Research Institute for their invaluable supports for the study.

\section{References:}

1. Das UN. Is Metabolic Syndrome $X$ an Inflammatory Condition?. Exp Biol Med 2002; 227: 989-97.

2. Tomiyama H, Koji Y, Yambe M, Motobe K, Shiina K, Gulnisa Z, et al. Elevated C-Reactive Protein Augments Increased Arterial Stiffness in Subjects With the Metabolic Syndrome. Hypertension 2005; 45: 997-1003.

3. Godsland IF, Crook D, Paroudler AJ, Stevenson JC. Hemostatic Risk Factor and Insulin Sensitivity, Regional Body Fat Distribution and the Metabolic Syndrome. J Clin Endocrinol Metab 2005; 90: 190-7.

4. Anand SS, Yi Q, Gerstein H, Lonn E, Jacobs R, Vuksan V, et al. Relationship of Metabolic Syndrome and Fibrinolytic Dysfunction to Cardiovascular Disease. Circulation 2003; 108: 420-5.

5. Stegenga ME, Van Der Crabben SN, Levi M. Hyperglycemia Stimulates Coagulation, Whereas Hyperinsulinemia Impairs Fibrinolysis in Healthy Humans. Diabetes 2006; 55: 1807 12.

6. Sakkinen PA, Cushman M, Psaty BM, Rodriguez B, Boineau R, Kuller LH, et al. Relationship of Plasmin Generation to
Cardiovascular Disease Risk Factor in Elderly Men and Women. Arterioscler Thromb Vasc Biol 1999; 19: 499-505.

7. Aso $\mathrm{Y}$, Wakabayashi $\mathrm{S}$, Yamamoto $\mathrm{R}$, Matsumoto $\mathrm{R}$, Takebayashi K, Inukai T. Metabolic Syndrome Accompanied by Hypercholesterolemia Is Strongly Associated With Proinflammatory State and Impairment of Fibrinolysis in Patients with Type 2 Diabetes. Diabetes Care 2005; 28 : 2211-6.

8. Hryszko T, Malyszko J, Malyszko JS, Brzosko S, Pawlak K, Mysliwiec M. A Possible role of Thrombin-activatable Fibrinolysis Inhibitor in Disturbances of Fibrinolytic System in Renal Transplant Recipients. Nephrol Dial Transplant 2001; 16: 1692-6.

9. Cabalerro AE. Endothelial Dysfunction in Obesity and Insulin Resistance : A Road to Diabetes and Heart Disesae. Obes Res 2003; 11: 1278-89.

10. Wellen KE, Hotamisligil GS. Obesity-Induced Inflammatory Changes in Adipose Tissue. J Clin Invest 2003; 112: 1785-8.

11. Speidl WS, Zeiner A, Nikfardjam M, Geppert A, Jordanova $\mathrm{N}$, Niessner A, et al. An Increase of C Reactive Protein is Associated with Enhanced Activation of Endogenous FibrinolysisatBaseline butAn Impaired Endothelialfibrinolytic Response After Venous Occlusion. J. Am. Coll. Cardiol 2005; 45: 30-4.

12. Henry M, Aubert $H$, Morange PE, Nanni I, Alessi MC, Tiret L, et al. Identification of polymorphisms in the promoter and the 39 region of the TAFI gene: evidence that plasma TAFI antigen levels are strongly genetically controlled. Blood 2001; 97:2053-8

13. Scroeder V, Kucher N, Kohler HP. Role of Thrombin Activatable Fibrinolysis Inhibitor (TAFI) in Patients withAcute Pulmonary Embolism. Journal of Thrombosis and Haemostasis 2003; 1: 492-3.

14. Kujawski MRF, Hoppensteadt D, lqbal I, Demir M, Tobu M, Fareed D, Fareed J. Role of PAI-1 and TAFI in the Mediation of Fibrinolytic Deficit in cacner Patients. Journal of Clinical Oncology 2004; 22.

15. Vague IJ, Renucci JF, Grimaux RM, Morange PE, Gouvernet $\mathrm{J}$, Gourmelin Y, et al. Thrombin Activatable Fibrinolysis Inhibitor Antigen Levels and Cardiovascular Risk Factors. Arterioscler Thromb Vasc Biol 2000; 20: 2156-61.

16. Marx PF, Meijers JCM. TAFI : Regulating the cross talk between coagulation and fibrinolyisis. J Lab Med 2005; 29: 412-20. 